\title{
POSSÍVEIS MECANISMOS DE AÇÃO DOS GRÃOS INTEGRAIS NA PREVENÇÃO DO CÂNCER COLORRETAL
}

\author{
Possible mechanisms of action of whole grains in \\ colorectal cancer prevention
}

\author{
Patrícia Haas ${ }^{1}$ \\ Alex Amorin Anton ${ }^{2}$ \\ AderleySerenitaSartori ${ }^{3}$ \\ AliciadeFrancisco ${ }^{4}$
}

\section{Introdução}

A diversidade e a complexidade dos fatores associados à alimentação dificultam a investigação da relação alimentação e câncer. No entanto, estudos epidemiológicos corroboram a associação de fatores dietéticos com a proteção contra o câncer e também com a promoção da carcinogênese. Entre os fatores alimentares identificados que podem diminuir o risco de desenvolvimento de câncer estão as frutas e vegetais ricos em substâncias antioxidantes, principalmente o beta-caroteno e a vitamina $\mathrm{C}$, que protegeriam o organismo dos efeitos nocivos dos radicais livres, bem como os grãos integrais (1).

No ano de 1999, a American Association of Cereal Chemists (AACC) alegou a seguinte definição para grãos integrais: "Grãos integrais consistem da cariopse intacta, quebrada, moída ou em flocos, cujos componentes botânicos principais (endosperma, casca e gérmen) encontram-se relativamente nas mesmas proporções que se encontrariam na cariopse intacta". Atualmente, essa definição está sendo novamente avaliada e existem perspectivas de algumas mudanças do conceito citado. O endosperma constitui aproximadamente $83 \%$ do peso do grão e contém a maior parte de proteínas, carboidratos, ferro como também algumas vitaminas do complexo B, tais como riboflavina, niacina e a tiamina, quando comparado ao grão inteiro. A casca corresponde aproximadamente a $14,5 \%$ do peso do grão, contendo uma pequena quantidade de proteínas, grande quantidade de vitaminas do complexo B, traços de minerais e fibra alimentar. O gérmen corresponde a aproximadamente $2,5 \%$ do peso do grão e é o embrião da semente. Contém mínimas quantidades de proteínas, mas grande parte das vitaminas e traços de minerais (2).

\footnotetext{
Doutora em Ciência dos Alimentos, Laboratório de Ciência e Tecnologia de Cereais (CERES), Departamento de Ciência e Tecnologia de Alimentos (CAL), Centro de Ciências Agrárias (CCA), Universidade Federal de Santa Catarina (UFSC). e-mail: haas@ccs.ufsc.br

Mestrando em Food Science, Faculty of Agriculture \& Food Sciences, University of Manitoba, Winnipeg, Canada. e-mail: aamorin@gmail.com Doutora em Ciência dos Alimentos, Universidade Federal de Santa Catarina (UFSC). e-mail: aderley@hotmail.com

Prof $^{a}$ do Programa de Pós-Graduação em Ciência dos Alimentos, CERES/CAL/CCA/UFSC, Florianópolis (SC). e-mail: aliciadf@gmail.com
} 
Muitos componentes da alimentação têm sido associados com o processo de desenvolvimento do câncer, principalmente o câncer de mama, câncer colorretal (CCR), próstata, esôfago e estômago. A relação entre o consumo de certos alimentos e o risco de desenvolver câncer possui evidência científica apesar da complexidade dos fatores que estão associados à ingestão dos alimentos, como a conservação, o preparo, o tipo e quantidade de alimento consumido $(3,4)$. De todos os casos de câncer, cerca de $80 \%$ a 90\% estão associados a fatores ambientais. O desenvolvimento de várias formas mais comuns de câncer resulta de uma interação entre fatores endógenos e ambientais, sendo a dieta o mais notável desses fatores. É estimado que cerca de 35\% dos diversos tipos de câncer ocorrem em razão de dietas inadequadas. É possível identificar, por meio de estudos epidemiológicos, associações relevantes entre alguns padrões alimentares observados em diferentes regiões do mundo e a prevalência de câncer $(5,6,7)$.

Há algumas décadas tem sido enfatizado o efeito protetor da fibra alimentar contra o CCR (8). Este conceito foi sugerido por BURKITT (1971) (8), que relacionou a elevada ingestão de fibras com a baixa incidência desse tipo de câncer entre a população do leste da África. Alguns autores explicam a patogênese do câncer colorretal em relação à dieta, devido à acentuada influência exercida na atividade da microflora intestinal, onde a presença de dietas ricas em gordura e pobres em fibra favorece a proliferação bacteriana e a conseqüente degradação dos ácidos biliares, produzindo agentes carcinogênicos potenciais. A presença de dietas pobres em fibra provoca retardamento da função intestinal ocasionando prolongamento de tempo de contato com a mucosa intestinal de agentes carcinogênico presentes no conteúdo fecal (9). Os alimentos associados com riscos baixos de vários tipos de cânceres são os tipicamente incluídos na dieta mediterrânea. Esta dieta é caracterizada por um consumo alto de frutas, verduras, cereais e alimentos integrais, assim como peixe, e uma menor ingestão de carboidratos refinados e carne vermelha, sendo que o azeite deve substituir gorduras saturadas (10).

Segundo a Organização Mundial de Saúde, a distribuição de mortes por cânceres pelo mundo não é homogênea. $O$ câncer é a segunda causa principal de óbito no mundo, sendo responsável por mais de 60 milhões de mortes anualmente. No período de 1960 a 2000 , os dados mostraram um aumento de $15 \%$ para $25 \%$ de mortalidade por câncer nos países desenvolvidos. Já nos países em desenvolvimento, observaram-se taxas menores e crescentes, que alcançaram 6\% em 1985; 9\% em 1997, com uma expectativa de aumentar, de aproximadamente 5,4 milhões de casos registrados em 2000, para 9,3 milhões de casos em 2020, de acordo com as projeções populacionais $(6,7,11)$.

As pessoas que vivem em centros urbanos dependem mais de alimentos e bebidas industrializados e aos poucos, possivelmente, vão abandonando antigos estilos de vida. Essa mudança também ocorre com relação aos tipos de ocupação, fazendo com que as pessoas passem a ser mais sedentárias nas cidades, em contraste com as atividades que geram maior atividade física na zona rural. A combinação entre a adoção do padrão alimentar mais ocidental e níveis mais baixos de atividade física acarretam um aumento da incidência de obesidade com impacto na morbi-mortalidade por doenças crônico-degenerativas, como as doenças isquêmicas do coração, diabetes e câncer (12). O objetivo desta revisão bibliográfica é abordar as possibilidades sobre mecanismos de ação da prevenção dos grãos integrais para o câncer colorretal publicadas e referendadas pela comunidade científica.

\section{Possíveis mecanismos de ação dos grãos integrais na prevenção do câncer colorretal}

Vários mecanismos têm sido apontados para explicar o papel das fibras no processo de carcinogênese do CCR, sendo que os cientistas já propõem algumas possibilidades. Estas possibilidades dizem respeito aos efeitos fisiológicos e mecânicos das fibras que por meio do aumento do volume das fezes, ou pela diminuição do tempo de trânsito intestinal, facilitariam a remoção dos carcinógenos, co-carcinógenos e/ou promotores do tumor, diminuindo o tempo de contato desses agentes, presentes no conteúdo fecal com a mucosa do intestino.

Outro mecanismo considera a capacidade físico-química da fibra de se ligar aos ácidos biliares, retardando ou reduzindo a absorção de lipídios. O terceiro mecanismo proposto está relacionado com a capacidade das fibras de servir como substrato para a fermentação das bactérias presentes no cólon, influenciando a ecologia intestinal e gerando produtos finais fisiologicamente ativos. Essa fermentação contribui para o aumento da massa bacteriana e, conseqüentemente, para o aumento do volume das 

semelhantes àsfibras

Fibras insolúveis (lignina, celulose, hemicelulose tipo B)

Propriedades Físicas/Químicas

Não hidrossolúveis;

Não fermentáveis ;

Não-viscosas.

Reduzem a constipação: aumentam a massa fecal, a consistência das fezes e a freqüência da evacuação e aceleram o trânsito intestinal ${ }^{\text {b }}$;

Promovem o desenvolvimento da mucosa do íleo e do cólon, intensificam a proteção contra a infecção bacteriana.

Fibras solúveis (pectinas, gomas, mucilagens ${ }^{(\mathrm{c})}$, beta-glucano, hemicelulose tipo A)

Hidrossolúveis;

Fermentáveis ;

Viscosas / gelificante ${ }^{\mathrm{d}}$.

Retardam o esvaziamento gástrico e o trânsito no intestino delgado (e), modulam a motilidade gastrintestinal e aumentam a massa, volume e consistência das fezes (efeitos brandos);

Reduzem a diarréia (absorção de água aumentada) e promovem o desenvolvimento da mucosa do íleo e do cólon; proporcionam energia à mucosa intestinal, diminuem o $\mathrm{pH}$ do cólon aumentam a proteção contra infecção (função de barreira, imunidade);

Aumenta a tolerância à glicose $\mathrm{e}^{\mathrm{e}}$, diminuem os níveis elevados de colesterol total e de $\mathrm{LDL}^{\mathrm{e}}$.

\section{Inulina, frutooligossacarídeos}

\section{Propriedades Físicas/Químicas}

\section{Benefícios fisiológicos}

Hidrossolúveis;

Fermentáveis;

Não-viscosas.

Promovem uma flora intestinal saudável (efeito prebiótico/bifidogênico);

Diminuem o pH do cólon (produção de ácido láctico), aumentam a proteção contra infecção (função de barreira, imunidade);

Reduzem a diarréia e a constipação, diminuem os altos níveis de glicose do sangue e melhoram o perfil de lipídeos do sangue.

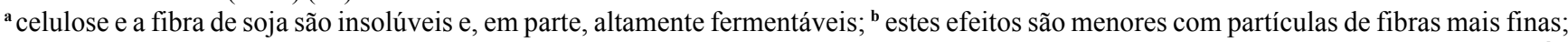
c psilio é uma mucilagem que retém água sem ser muito solúvel e tem propriedades laxativas semelhantes àquelas das fibras insolúveis; ${ }^{\mathrm{d}} \mathrm{a}$ hemicelulose tem uma baixa viscosidade. A hidrólise da goma guar reduz bastante sua viscosidade; ${ }^{\mathrm{e}}$ este efeito aumenta com a viscosidade (isto é, maior com gomas e pectinas). 
fezes, eleva a produção de ácidos graxos de cadeia curta (acetato, propionato e butirato) que alteram o $\mathrm{pH} \mathrm{e} \mathrm{a}$ microflora intestinal, exercendo efeitos fisiológicos benéficos. Também se observa a promoção de absorção de sódio e água, fato importante para a conservação de eletrólitos. O butirato parece exercer as seguintes funções: fornecer energia na mucosa intestinal; estimular diferenciação celular e multiplicação das células basais; aumentar a superfície de contato das microvilosidades; aumentar a absorção de cálcio e atividade pancreática e, ainda, aumentar as secreções das enzimas digestivas $(13,14,15,16,17)$.

$\mathrm{O}$ acetato, o propionato e o butirato são os principais ácidos graxos voláteis ( $\mathrm{AGV}$ ), produzidos pela fermentação das fibras. A primeira conseqüência dessa produção de AGV é a acidificação do cólon, o que pode evitar a proliferação excessiva de bactérias indesejadas (por exemplo, os clostrídios). $\mathrm{O}$ acetato e a maior parte do propionato atingem o fígado por meio do sangue portal. O propionato inibe a síntese hepática do colesterol e, embora ainda haja algumas controvérsias no mecanismo exato da síntese de ácidos biliares, triglicerídeos e LDL-c em relação às fibras, o papel preventivo de diferentes fibras na redução do colesterol plasmático vem-se confirmando cada vez mais. $\mathrm{O}$ butirato é absorvido pelas células do cólon e utilizado como energia prontamente disponível por essas células. A absorção do butirato é acoplada à reabsorção de sódio e água e pode, assim, proporcionar um efeito antidiarréico. O efeito dos AGV sobre a integridade das células do cólon e a reabsorção de água pode ter uma importância crucial para a diarréia associada a antibióticos, quando a flora normal é afetada pela droga. Durante a terapia antibiótica, espécies bacterianas potencialmente patogênicas normalmente presentes em pequenos números e que são resistentes aos antibióticos podem proliferar. A proliferação bacteriana excessiva resultante pode causar má absorção e translocação bacteriana. As fibras solúveis podem ajudar a controlar a proliferação bacteriana excessiva mantendo os níveis de AGV que acidificam o conteúdo do cólon, proporcionando energia às células do cólon, mantendo a integridade intestinal e apoiando o desenvolvimento de bactérias normais saudáveis a expensas das bactérias patogênicas $(18,19,20)$.

As dietas ricas em gorduras ocasionam aumento dos ácidos graxos e dos ácidos biliares nas fezes. Além disso, poderiam levar a mudança na composição dos ácidos biliares e influenciar a atividade metabólica da microflora intestinal, possibilitando que substâncias promotoras de tumor sejam produzidas a partir desses ácidos. No lúmen do cólon, sugere-se que os ácidos graxos solúveis e ácidos biliares poderiam interagir com o epitélio do cólon, induzindo o aparecimento de lesões e o aumento da proliferação celular, atuando como agentes promotores do câncer de cólon $(16,21,22)$.

Existe também a possibilidade de ocorrer a redução de estrogênios bioativos no sangue. É fato que dietas ricas em fibras estão associadas com a alteração da flora colônica, atuando na regulação da recirculação enterohepática de estrogênios, de tal forma que a quantidade de estrogênio excretado é aumentada. Mecanismos alternativos ressaltam a importância de outros constituintes da fibra, como o fitato (inositol6-fosfato), que merece ter sua ação anticarcinogênica investigada, visto que há diversas evidências acerca da variedade de efeitos biologicamente significantes, na tumorigênese quimicamente induzida. Dados epidemiológicos muitas vezes não corroboram com os dados experimentais. Talvez tal fato decorra da dificuldade na quantificação da ingestão de fibras, em decorrência dos falhos instrumentos para avaliação do consumo alimentar (23).

A ingestão de fibras em alta quantidade pode provocar uma redução na absorção dos minerais, cálcio, zinco, ferro, cobre, magnésio e fósforo, reduzindo a biodisponibilidade de nutrientes importantes. Os efeitos da fibra alimentar (FA) nos minerais podem ser mais acentuados em estados fisiológicos especiais como crescimento, gestação, lactação e nos idosos, quando as dietas são deficientes nesses nutrientes. As FA terão seu papel benéfico mediante o bom funcionamento intestinal se a ingestão de líquidos ao dia estiver entre 1000 a $2000 \mathrm{ml}$. Alimentos ricos em FA necessitam de mais tempo para serem mastigados. Esta mastigação prolongada induz a uma maior produção de suco gástrico, que juntamente com a saliva e o alimento vão provocar uma elevação do volume do conteúdo estomacal, aumentando a sensação de saciedade. Vale notar a advertência da Organização Mundial de Saúde no sentido de que medidas dietéticas para prevenção de doenças crônicas precisam ser adotadas cedo na vida e ao longo dela (24).

Estudos demonstram também que uma alimentação pobre em fibras, com altos teores de gorduras e altos níveis calóricos, está relacionada a um maior risco para o desenvolvimento de CCR, 
possivelmente porque, sem a ingestão de fibras, o ritmo intestinal desacelera, favorecendo uma exposição mais demorada da mucosa aos agentes cancerígenos encontrados no conteúdo intestinal. Em relação a cânceres de mama e próstata, a ingestão de gordura pode alterar os níveis de hormônio no sangue, aumentando o risco da doença. Há vários estudos epidemiológicos que sugerem a associação de dieta rica em gordura, principalmente a saturada, com um maior risco de se desenvolver esses tipos de câncer em regiões desenvolvidas, principalmente em países do Ocidente, onde o consumo de alimentos ricos em gordura é alto. Já os cânceres de estômago e de esôfago ocorrem mais freqüentemente em alguns países do Oriente e em regiões pobres, onde não há meios adequados de conservação dos alimentos, o que torna comum o uso de picles, defumados e alimentos conservados em sal (25).

Não é claro se a fermentação anaeróbica de fibra dietética solúvel pela microflora no cólon inibe ou promove a carcinogênese do cólon. Por exemplo, polissacarídeos de goma de fibra causam colapso na microflora intestinal devido aos ácidos acético, propiônico e butírico; sendo que o último acredita-se ser o mediador principal dos efeitos de fibras dietéticas na mucosa (aumentando o crescimento da mucosa e causando a diferenciação epitelial e apoptose, além de inibir o desenvolvimento do tumor), provavelmente pela ação de isoflavonas, enquanto outros estudos mostraram um risco aumentado de crescimento de tumor no cólon quando cobaias consumiram legumes. Os resultados de estudos do efeito de fibras diferentes no desenvolvimento do CCR em animais sugerem que o efeito inibitório depende do tipo de fibra ingerida (26).

Murtaugh et al. (2006) (9) publicaram que fatores de risco modificáveis na etiologia do câncer colorretal e suas interações com susceptibilidade genética são de interesse particular na presente pesquisa. O polimorfismo dos receptores funcionais de vitamina $\mathrm{D}$ (VDR) pode influenciar a carcinogênese mediante a modificação do crescimento celular, proteção contra o estresse oxidativo, efeito celular, ou por meio das vias dos fatores de crescimento insulina ou "tipoinsulina". Investigamos as interações entre alimentos (laticínios, carne crua e processada, e grãos integrais e processados) e fatores dietéticos (relação sacaroseaçúcar e índice glicêmico) relacionados à resistência à insulina com o polimorfismo FokI do gene VDR e risco de desenvolvimento de câncer de colorretal. Os dados (dieta, antropometria e estilo de vida) e o DNA foram obtidos de um estudo caso-controle de câncer de colon (1698 casos e 1861 controles) e câncer retal (752 casos e 960 controles) no norte da Califórnia, Utah, e na área metropolitana das cidades gêmeas, em Minnesota (apenas câncer de colon). Modelos de regressão de logística incondicional foram ajustados para tabagismo, raça, sexo, idade, índice de massa corpórea, atividade física, consumo de energia, fibra dietética e cálcio. O risco mais baixo de câncer de colon foi observado com os genotipos Ff/ff FokI e uma baixa relação sacarose-fibra. O risco de câncer retal diminuiu com o maior consumo de laticínios e aumentou com o consumo de carne crua ou processada. Fatores de risco dietéticos modificáveis podem ser diferencialmente importantes entre indivíduos por meio do genotipo VDR e pode agir pela via da insulina para influenciar o risco de câncer de colon por meio de gordura, cálcio, ou outras formas para influenciar o risco de câncer retal (27).

Evidências epidemiológicas têm demonstrado que existe uma relação entre o consumo de frutas frescas e vegetais e a menor incidência de cânceres originários em epitélios de revestimento (de cavidade bucal, esôfago, estômago e pulmão). Tem se evidenciado que a vitamina A protege contra o câncer da cavidade bucal, faringe, laringe e pulmão e é possível que a vitamina $\mathrm{E}$ diminua o risco de se desenvolver o câncer. Embora a vitamina $\mathrm{C}$ bloqueie a formação endógena de nitrosaminas, no trato gastrintestinal não há evidências de que a ingestão maior dessa vitamina possa prevenir o câncer intestinal $(28,29)$.

\section{Conclusão}

Considerando os possíveis mecanismos de ação dos grãos integrais na prevenção contra o câncer colorretal (CCR) apontados pela literatura, é possível observar a relevância desse seguimento de pesquisa. As evidências dessa forma de prevenção indicam que a ingestão contínua e em quantidade adequada de grãos integrais possibilita essa proteção. A indicação da comunidade científica é de que sejam ingeridos $30 \mathrm{~g} / \mathrm{dia}$. Os mecanismos apontados até então reafirmam essa importância e explicam essas possibilidades da ação dos grãos integrais, no entanto, parecem necessários mais estudos elucidando definitivamente como ocorre a proteção contra o CCR em humanos quando ingeridos os grãos integrais. 


\section{Referências}

1. American Cancer Society. Guidelines on diet, nutrition and cancer prevention: reducing the risk of cancer with healthy food choices and physical activity American Cancer Society dietary guidelines advisory committee, Washington DC; 1996.

2. American Association of Cereal Chemists. [homepage on the Internet]. St. Paul: 2005. [update 2005; cited 2005 jun]. Available from: http://www.aaccnet.org/

3. Ministério da Saúde. Instituto Nacional de Câncer. Coordenação nacional de controle de tabagismo CONTAPP: 'Falando Sobre Câncer e Seus Fatores de Risco'. Rio de Janeiro; 1996.

4. INCA/MS. Prevenção e Controle de Câncer. Revista Brasileira de Cancerologia. 2002; 48(3):317-332.

5. Glanz K. Behavioral research contributions and needs in cancer prevention and control: Dietary change. Prev Med. 1997; 26(2):S43-S55.

6. Ribeiro LR, Salvadori DMF, Marques EK. Mutagênese Ambiental. Canoas: ULBRA; 2003.

7. Garófolo A, Avesani CV, Camargo KG, Barros ME, Silva SRJ, Taddei JAAC, Sigulem DM. Dieta e câncer: um enfoque epidemiológico. Rev Nutr. 2004; 17(4):491-505.

8. Burkitt DP. Epidemiology of cancer of the colon and rectum. Cancer. 1971; 28(7):3-13.

9. Lopes EF, Deviri SCN, Mendez MHM. The importance of diet in the epidemiology of cancer of the colon and rectum. Rev Saúde Públ. 1984; 18:405-410.

10. Fernández E, Gallus S, La Vecchia C. Nutrition and cancer risk: an overview. Journal of the British Menopause Society. 2006; 12(4):139-141.

11. World Health Organization. National cancer control programs: Policies and managerial guidelines. $2^{\text {nd }}$ ed. Geneva: WHO; 2002.

12. Mondine L, Monteiro CA. Mudanças no padrão de alimentação da população urbana brasileira: 1962-1988. Rev. Saúde Pública. 1994; 28(6):433-9.
13. Klurfeld DM. Dietary Fiber-Mediated Mechanisms in Carcinogenesis. Cancer Research. 1992; 52:2055s-2059s.

14. Howe GR, Benito E, Castelleto R, Cornée J, Estève $\mathrm{J}$, Gallagher RP, et al. Dietary Intake of Fiber and Decreased Risk of Cancers of the Colon and Rectum: Evidence from the Combined Analysis of 13 Case-Control Studies. Journal of the National Cancer Institute. 1992; 84(24):1887-96.

15. Ausman LM. Fiber and Colon Cancer: Does the Current Evidence Justify a Preventive Policy? Nutrition Reviews. 1993; 51(2):57-63.

16. Neves FJ. Mortalidade por câncer de colon e reto e perfil de consumo alimentar em capitais brasileiras. 2002 [dissertação]. São Paulo: Fundação Oswaldo Cruz, Escola Nacional de Saúde Pública; 2002.

17. Slavin JL. Whole grain and human health. Nutrition Research Rewiews. 2004; 17:99-110.

18. Gibson GR, Roberfroid MB. Dietary Modulation of the Human Colonic Microbiota: Introducing the Concept of Prebiotics. J Nutr. 1995; 125:1401-12.

19. Rique ABR, Soares EA, Meirelles CM. Nutrition and exercise on cardiovascular disease prevention and control. Rev Bras Med Esporte. 2002; 8(6):244-254.

20. Saad FMOB, Salgarello RM, Gurian TM. Recentes avanços na Nutrição de Cães e Gatos (palestra - texto em anais). In: $2^{\circ}$ Simpósio sobre Nutrição de animais de Estimação, 2003; Campinas: [s. n.]. 2003.

21. Wynder EL \& Shigematsu T. Environmental Factors of Cancer of the Colon and Rectum. Câncer. 1967; 20(9):1520-61.

22. Holt PR. Studies of Calcium in Food Supplements in Humans. Annals New York Academy of Sciences. 1999; 889:128-37.

23. Padilha PC, Pinheiro RL. O Papel dos Alimentos Funcionais na Prevenção e Controle do Câncer de Mama. Revista Brasileira de Cancerologia. 2004; 50(3): 251-260.

24. Garbelotti ML,Torres EF, Marsiglia DAP. Papel da fibra na alimentação. Bol. Inst. Adolfo Lutz. 2003; 1:3-28. 
25. Levi F, Pasche C, La Vecchia C, Lucchini F, Franceschi S. Food groups and colorectal cancer risk. British Journal Of Cancer. 1999; 79(78):1283-1287.

26. Ahmed FE. Effect of Diet, Life Style, and Other Environmental/Chemopreventive Factors on Colorectal Cancer Development, and Assessment of the Risks. J Environ Sci Health C Environ Carcinog Ecotoxicol Rev. 2004; 22(2):1-57.

27. Murtaugh MA, Sweeney C, Ma Khe-Ni, Potter JD, Caan BJ, Wolff RK.,Slattery ML. Vitamin D Receptor Gene Polymorphisms, Dietary Promotion of Insulin Resistance, and Colon and Rectal Cancer. Nutrition and Câncer. 2006; 55(1):35-43.
28. Medrado-Faria MA, Rodrigues de Almeida JW, Zanetta DM. Gastric and colorectal cancer mortality in an urban and industrialized area of Brazil. Rev Hosp Clin Fac Méd. 2001; 56(2):47-52.

29. Guerra MR, Gallo CVM, Azevedo G, Mendonça S. Risco de câncer no Brasil: tendências e estudos epidemiológicos mais recentes. Revista Brasileira de Cancerologia. 2005; 51(3):227-234.

Recebido em/Received in: July 28, 2006 Aceito em/Accepted in: August 31, 2006 